\title{
DA AUTOXESTIÓN ÁS POLÍTICAS CULTURAIS. A ARTE GALEGA NOS ANOS DA TRANSICIÓN
}

Data recepción: 2010/05/19

Data aceptación: 2010/06/08

Contacto autor: miguelanxo.rodriguez@usc.es
Miguel Anxo Rodríguez González

Universidade de Santiago de Compostela

RESUMO

O período que vai desde os primeiros anos 70 ata 1984 supuxo para a arte galega unha fase intensa en experiencias autoxestionadas, onde os creadores montaron iniciativas expositivas e divulgativas que terían sido máis ben competencia das institucións. A amalgama estilística e o traballo en precario e colectivo caracterizaron estas experiencias. Coa instauración da Xunta de Galicia isto remata, botando a andar as políticas culturais en sentido moderno, con xestión a cargo de profesionais. A actual contraposición entre promoción institucional e creación crítica e implicada leva a revisar ese período de efervescencia, precariedade e moita ilusión que coincidíu coa Transición.

Palabras clave: autoxestión, grupos e colectivos artísticos, Galicia, políticas culturais

ABSTRACT

The period between the death of General Francisco Franco (1975) and 1984 yielded many self-managed events in Galician art, with artists embarking on exhibition and dissemination initiatives that would ordinarily be the responsibility of public institutions. These events were characterised by an amalgam of styles and group projects undertaken in difficult working conditions. The creation of the Regional Government of Galicia brought an end to this situation, with the introduction of modern cultural policies managed by professionals. The current clash between institutional promotion and critical and committed creation leads us to look back at this period of intense creativity, precariousness and excitement, one that coincided with the transition to democracy.

Keywords: self-management, artistic groups and collectives, Galicia, cultural policies

En novembro de 2002 o Museo de Arte Contemporánea de Vigo (MARCO) abríu as súas portas ao público cunha exposición que revisaba un período de efervescencia cultural sen precedentes en Vigo e en Galicia, a primeira metade dos oitenta, coa exposición "Atlántica. Vigo. 1980-1986" 1 . Aqueles foran anos de precariedade e de ilusións, de esforzo compartido e iniciativas culturais "amateurs" e autoxestionadas, cando aínda os museos non estaban, e a estrutura de apoio ás artes era moi endeble. Pero o que puido ter sido unha festa, un emotivo reencontro dos protagonistas daqueles intensos anos de creatividade fresca e desinhibida, e de iniciativas artísticas ilusionantes, acabou motivando unha agria polémica que saltou aos medios de comunicación e deu lugar a tensos debates entre os artistas implicados. Celebráronse unhas xornadas para tentar reflexionar con serenidade sobre o ocorrido nos oitenta e sobre a polémica revisión, pero nestas os desencontros e reproches estiveron tan presentes como os recordos amables ${ }^{2}$.

Os reproches dirixíronse particularmente cara ao comisario da exposición -Xosé Antón Castro- e cara a un dos artistas que máis material documental aportou a esta —Antón Patiñoque sería tamén ampliamente representado cos seus cadros. Acusábanos de rendabilizar os éxitos do colectivo de artistas que protagonizaron o movemento Atlántica nos oitenta e de configurar unha historia moi personalista, cando "aquela historia" —argumentaban os críticos- a fixeran entre todos. Acusábase ao comisario de 
darlle moito máis protagonismo aos artistas que logo tiveron máis éxito comercial e desprazar cara as marxes a outros. Alguns dos artistas asistentes ás xornadas —en concreto Ignacio Basallo e Antón Lamazares- chegaron a indicar que, para ser fieis ao espírito de Atlántica, a exposición do MARCO debera de ter sido organizada polo colectivo. A isto respostou Xosé Antón Castro que iso tería sido tan absurdo como pedir a xogadores de fúbol da selección que se seleccionasen a si mesmos ${ }^{3}$. A autoxestión, viña a indicar Castro, non ten hoxe sentido neste mundo da arte actual tan profesionalizado. Fronte ao cal volvían a replicar os artistas: pero entón isto que está aquí montado xa non é Atlántica, é tan só a historia duns poucos membros relevantes dese movemento (Fig. 1).

Tería sido hoxe posible algo como Atlántica? O espírito de iniciativas autoxestionadas difícilmente pode ser representado cunha exposición das actualmente organizadas nos museos de arte contemporánea. O que os mencionados debates estaban ofrecendo era non só a ilustración de rivalidades persoais ou egos de artistas: tratábase da confrontación entre dúas concepcións moi diferentes da idea de "mundo da arte": unha baseada nas relacións persoais de artista, galerista e medios de comunicación, e outra dependente do traballo de comisarios de exposicións e de xestores de centros; e Xosé Antón Castro servíu de bisagra entre eses dous mundos.

\section{Case todo estaba por facer}

Vigo e A Coruña concentraron entre mediados dos setenta e principios dos oitenta as principais iniciativas de cooperación entre artistas con vistas a aumentar a visibilidade da arte nova e a comunicación coa sociedade ${ }^{4}$. De crer aos artistas que protagonizaron as exposicións da Praza da Princesa no Vigo dos anos setenta e Atlántica, a principios dos oitenta, en Galicia non existía nada parecido a unha política cultural, e o panorama era desolador a nivel institucional. Nisto coincidían tanto os máis novos como os artistas experimentados deses anos -Antón Goyanes ou Manuel Moldes, por exemplo. As declaracións retrospectivas son do máis explícito: "naquel tempo non había nada" (Francisco Leiro); "naquel momento era máis difícil achegarse á arte" (Antón Patiño); "podemos dicir que o tema era tan triste que Atlántica aparenta máis do que en realidade foi" (Ánxel Huete) ${ }^{5}$. E cando os participantes nalgunha das mostras colectivas destes anos rememoran os traballos de organización e montaxe, atopamos unha realidade que hoxe sería moi difícil de entender, polo menos, se temos en conta que estamos a falar dos artistas máis prometedores do momento. Cando Leiro relata de xeito retrospectivo a organización da exposición Vinte artistas xoves galegos, en Santiago de Compostela, no adaptado para a ocasión convento de San Domingos de Bonaval, o ano 1977, chama a atención sobre a precariedade das condicións, que afectaban a transporte - facíanse cargo eles mesmos ou os familiares-. montaxe e instalacións ${ }^{6}$. Na mesma entrevista, Leiro apunta á contraposición existente na década dos setenta entre a arte "oficial" 7 e a dos mozos que se uniron para organizar Vinte artistas xoves galegos: a oficial era a representada nas Bienais de Pontevedra, nalgunhas galerías de arte e en salas pouco idóneas como a do Hostal dos Reis Católicos, en Santiago. Á situación pódenselle engadir outras realidades locais, como as de Vigo, coa sala da Caixa de Aforros, ou Ourense, coa sala do Museo Arqueolóxico. Pero en todo caso temos que falar de espazos institucionais ou galerías privadas pouco e mal acondicionadas para expoñer ${ }^{8}$.

Gabriel Plaza Molina, crítico de arte madrileño afincado en Galicia nos anos setenta, daba conta das carencias e falta de profesionalismo existente en galerías e salas de exposición dese tempo. Cando analizaba a situación na Coruña indicaba que as galerías eran poucas, pequenas e estaban case máis movidas por un afán altruísta que polas leis do mercado ${ }^{9}$, e o Concello mantiña unha actividade expositiva moi pouco rigorosa. Carencias institucionais que contrastarían —na súa interpretación- cunha proliferación de artistas interesantes, e de galerías de arte na cidade. No seu libro Arte en Galicia: la década del "boom" dedica louvanzas á obra de varios artistas abstractos (Molezún, Labra, Caruncho...) que xa tiñan exposto en Madrid, e alude á creación de novas galerías de arte nas cidades de Galicia. O feito é significativo, como significativa é a asociación entre arte abstracta, ou novas tendencias, e fortalecemento do mercado da arte. Nunha sociedade como a galega, cunha burgue- 


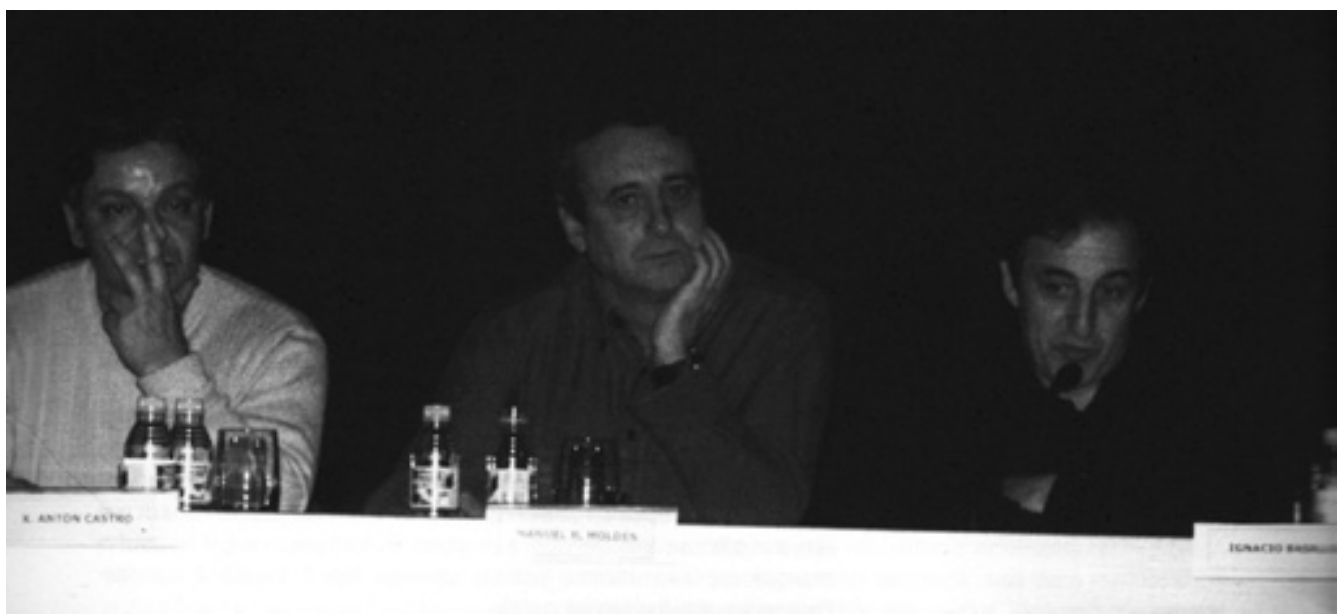

Fig. 1. Mesa de debate "Xornadas Atlánticas". Museo de Arte Contemporánea de Vigo (MARCO), 14 de marzo de 2003. De esquerda a dereita: Xosé Antón Castro, Manuel R. Moldes e Ignacio Basallo. Fotografía de Rafael Estévez.

sía que tradicionalmente era escasa e feble, e pouco dada ao coleccionismo de obras de arte, esta proliferación de galerías na década dos setenta representaba, o primeiro síntoma de modernización e homologación coa situación exterior ${ }^{10}$.

Nos setenta e primeiros oitenta en Galicia, a precariedade estableceuse fronte a un panorama institucional raquítico no que á cultura contemporánea se refire. O que faltaba era esa infraestrutura de apoio e promoción que se desenvolvería a partir da instauración do goberno autonómico. Se na actualidade percibimos unha loita pola independencia dos creadores fronte ao predominio das institucións e das industrias culturais, daquela, do que se trataba era de conquistar espazos de visibilidade e artellar un "mundo da arte".

Nestes anos nos que o debate teórico da arte nos achega a nocións tales como "traballo colectivo", "resistencia" (ás institucións culturais) ou "repolitización", achegándonos a algunhas das premisas de movementos de finais dos anos sesenta e dos setenta - o modelo dos situacionistas sempre presente-, é máis necesario que nunca revisar os parámetros nos que se desenvolveu a acción cultural deses anos. A precariedade, que tanto está a ocupar as reflexións dos "produtores culturais" de hoxendía, ten un vencello oculto coa vella precariedade desas décadas: aflora, de novo, aínda que hoxe contra o horizonte dunhas industrias e institucións culturais axigantadas, dunha escala que era difícil de imaxinar hai a penas trinta anos. A precariedade ten dúas caras: unha consciente, que nos indica un posicionamento resistente por parte de quen non quere ser integrado no sistema de produción cultural, e outra inconsciente, ou involuntaria, que alude á asimilación ás novas dinámicas do capitalismo postfordista, na súa vertente cultural. Segundo Isabell Lorey, podemos estar a falar hoxendía da precariedade como "modo asociado" ao sistema de organización do traballo creativo, impulsado polo mesmo sistema neoliberal nos últimos anos: desde os museos de arte contemporánea ás produtoras cinematográficas, asistimos ao predominio dunha estrita división entre postos de administración e xerencia estables, e traballo creativo precario. Esta inestabilidade aparece como submisa fronte aos ditados das institucións e industrias culturais ${ }^{11}$.

\section{A idea de grupo}

A capacidade organizativa e asociativa dos artistas destes anos será algo salientable, e acadará unha intensidade que non se volverá producir 
na nosa historia recente. Esta vontade de traballar xuntos fixo que as cuestións estéticas pasasen en ocasións a un segundo plano con vistas á normalización do mundo da arte: asumíase que o prioritario era artellar canles de exhibición da "modernidade" artística, pero logo non se acabou de concretar en que consistía esta, coexistindo modelos que ían desde a neofiguración ata a arte abstracta, e dentro desta, convivindo tendencias expresionistas con outras "normativas", máis frías. Por outra banda, estas actitudes solidarias e voluntaristas eran tamén as propias dun tempo de cambio social e político de grande calado, co tránsito da España franquista á democrática. Organizacións políticas ou sindicais antes perseguidas empezaban a saír á luz e víanse unhas posibilidades inmensas para a renovación cultural. A ilusión e a idea de compromiso van estar moi presentes nestes anos. Xavier Correa Corredoira, un dos artistas máis activos do foco coruñés, recordaba este momento desde a distancia:

Este fin de franquismo foi unha época onde verdadeiramente existían non só as posibilidades, senón a ilusión de que as cousas ían cambiar, que estavamos todos cambiando un pouco a realidade social, e esta cambiou, pero non para onde queriamos. Motivada por ese espellismo de cámbio havia unha vibración moi forte na nosa xeneración. Houvo xente que se apontou á política activa, que viveu intensamente a bohemia, o contracultural, o hipismo, as drogas, o rock and roll (sic) ${ }^{12}$.

$\mathrm{Na}$ Coruña houbo moito movemento asociativo desde os primeiros anos da década, con grupos como Sisga, A Carón, Gruporzán e A Galga, que tiveron polo xeral unha traxectoria breve, pero conseguiron crear un sentimento de comunidade entre os artistas novos (Fig. 2). Nestes colectivos xuntáronse escritores, deseñadores e artistas, cunha vontade común de defensa das tendencias máis avanzadas da creación, por unha banda, e por outra a mencionada de achegamento á poboación ${ }^{13}$. Sisga, un colectivo que naceu baixo o impulso de Fernando García Varela en 1973, posicionouse contra a mercantilización da arte e en defensa da recuperación da comunicación social. A heteroxeneidade estética no grupo (arte abstracta, neo-figuración e Op art) ficaba nun segundo plano fronte á vontade crítica —no político-, e divulgativa - no cultu$\mathrm{ral}^{14}$. Con este ánimo antimercantilista como bandeira -acentuado cos anos, por certobotarían a andar iniciativas en A Coruña, Ferrol e Santiago que aunaban exposicións, conferencias e debates sobre a arte moderna, chegando a asumir as funcións dos museos de arte contemporánea. Polos mesmos anos, no texto de presentación do folleto da Exposición de Pintura ao Aire Libre da Praza da Princesa (Vigo), de 1975, os artistas asinantes aludían directamente a este labor de reflexión e debate conxunto dos artistas para afrontar os problemas profesionais e a relación destes coa sociedade. A linguaxe do texto é moi da época:

...decatámonos de que a relación artepúblico e arte-pobo cómpre revisalas. Nós, neste contacto directo co público, queremos comezar, se ben moi modestamente, esta autocrítica e esta revisión (sic) ${ }^{15}$.

Revisando a historia de Sisga e o contexto creativo do momento, Xesús Ron alude a unha contradición ou febleza que levaban dentro de si os seus protagonistas: por unha banda presentábanse baixo un discurso marcadamente crítico e activista, pero por outra, nunca chegaron a ter unha conciencia política clara, unha participación efectiva na loita política fóra do ámbito cultural, e os seus discursos movéronse dentro dunha certa vaguedade. O artista "progre" e culto destes anos era visto como un "señorito" aos ollos da sociedade, mantido pola súa familia, sen oficio recoñecido, creador —en palabras de Ron-dun "universo paralelo de enorme potencial subversivo, pero que non tivo incidencia no plano político"16. Algunhas das súas peculiaridades lévannos a pensar nunha liña de continuidade coa bohemia decimonónica, tal e como fora caracterizada, por exemplo, por Walter Benjamin: radicalidade cultural e compromiso político, vaguedade ideolóxica, e as tabernas como ámbito preferencial de socialización ${ }^{17}$.

As exposicións de Atlántica repetiron algunhas características das que se viñan celebrando na viguesa Praza da Princesa desde 1968 e, de 


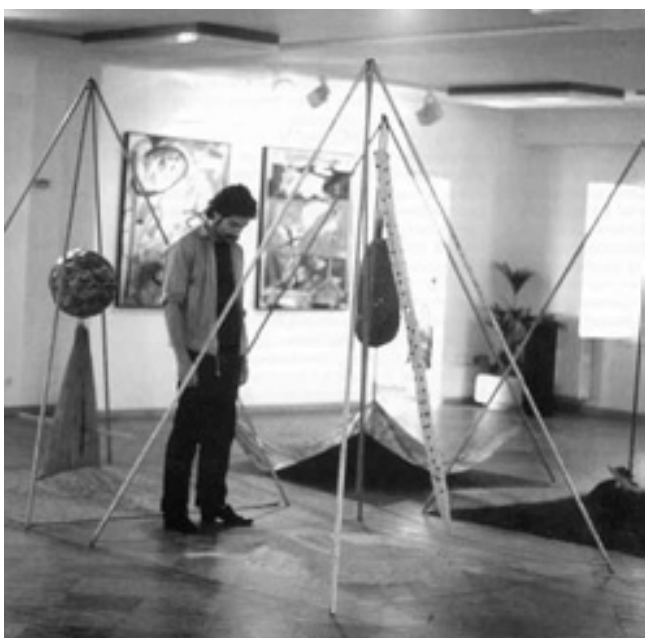

Fig. 2. Xavier Correa Corredoira ante a súa obra Lumeaugaterra. Atlántica, Baiona, 1980.

Fig. 3. Antón Patiño: Lixo urbano, óleo sobre tea, $146 \times 97$ cm., 1976. Colección particular.

feito, artistas como Ánxel Huete, Silverio Rivas, Antón Goyanes ou Antón Patiño están presentes en ámbalas dúas ${ }^{18}$. A capacidade de autoxestión era case absoluta, pois comprendía tódalas fases da realización, aínda que no apartado económico e na dispoñibilidade de espazos tiveron que contar co apoio de institucións públicas. Ángel llarri e Román Pereiro son pezas clave que fixeron de intermediarios entre artistas e institucións. En ámbolos dous casos os artistas prepararon o proxecto, seleccionaron artistas, encargáronse do transporte, do catálogo e da preparación de actividades paralelas, como debates ou conferencias ${ }^{19}$. As institucións que se prestaron a colaborar nestas iniciativas colectivas, presentaban carencias evidentes pola pouca bagaxe, a falta de experiencia e cartos, e sobre todo pola falta de profesionais. O caso da primeira mostra de Atlántica foi sintomático desta precariedade institucional: cando o coleccionista Román Pereiro lle propuxo ao entón alcalde da

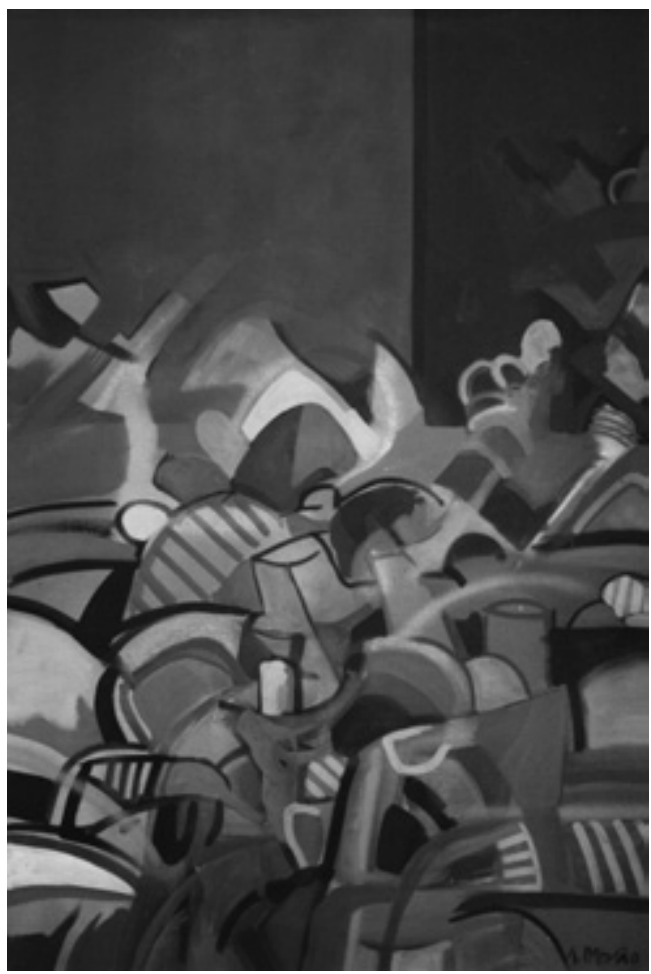

vila pontevedresa de Baiona a posibilidade de realizar unha exposición de arte contemporánea o rexedor contestou poñendo un espazo á súa disposición, pero advertindo que non podería apoiar economicamente nin en concepto de persoal, polas carencias do concello.

Estes eran tempos de arelas de modernidade e á vez defensa da cultura tradicional galega, cando os artistas se agrupaban para discutir e soñar novos modos de divulgación da arte contemporánea. As arelas de cambio político mesturábanse coas demandas dunha xestión máis democrática das accións culturais, e proliferaban certames, concertos, revistas, grupos literarios e artísticos. Antón Reixa, membro fundador do colectivo literario Rompente, resumía o ambiente da modernidade urbana coas seguintes palabras:

A socioloxía era que había moita xente para todo. Os teóricos trataban de explicar o funcionamento do mercado respecto á 
creación artística e á cultura de masas, o certo era que había moita xente en todos os sitios: os concertos estaban cheos, as inauguracións das exposicións eran verdadeiros acontecementos, os politicos disputábanse a compañía dos artistas. Esa era a novidade sociolóxica: era o momento da arte, da música pop, da moda, da modernidade, e coincidía cunha opinión pública que facía resistencia do bo humor e da festa ${ }^{20}$.

As colaboracións entre o pintor Antón Patiño e o poeta Antón Reixa amosaban que compartían unha vontade común de usar os códigos habituais dos medios e a "fala popular" de xeito totalmente irreverente e provocador ${ }^{21}$. En As ladillas do travesti, libro de poemas de Antón Reixa con ilustracións de Patiño, o tema do lixo urbano é explotado ata a saciedade, cunha estética da bricolaxe e superposición desordeada de imaxes dos medios e manipulacións (ampliacións, aplicación de cor) que distorsionan a súa lectura. O carácter urbano do libro era todo un xeito de posicionarse fronte á tradición literaria en galego, que habitualmente viña explotando imaxes sentimentais da paisaxe natural ou rura $^{22}$. E o lixo parecía ser un dos tópicos na pintura de Antón Patiño nestes anos de definición da estética propia (Fig. 3). O lixo lévanos á idea do descartado, ou expulsado pola sociedade, si, pero tamén de materiais de consumo masivo sometidos á acción humana. Acaía ben coa vocación de utilización das imaxes distorsionadas dos medios de masas, habitual na pintura de Patiño deses anos. Había semellanzas coa estética do Pop Art, e moito traballo de experimentación a partir de imaxes fotográficas que levaba cara a configuracións abstractas.

Estas experiencias compartidas hainas que relacionar coa cultura urbana que emerxía nas cidades europeas desde había unha década, con novas formas que desafiaban os códigos de comportamento socialmente establecidos. Estas formas de cultura xuvenil manifestábanse en estilos musicais e formas de vestir vistas en moitos casos como irreverentes. Movementos como o punk ou os rastas mereceron a atención de investigadores relacionados cos Estudos Culturais, como Dick Hebdige, quen conceptualizou estas manifestacións estéticas como "subcultu- ras" $^{23}$. Segundo este autor, a subcultura debe ser entendida como unha "forma simbólica de violación da orde social" que implica a adopción de códigos de comportamento e estilos no vestir moi diferenciados, elaborados a partir de materiais reutilizados de xeito atípico e provocador. $A$ estética do bricoleur urbano adiviñábase tanto na moda como noutras manifestacións culturais destes grupos; formas de bricolaxe irritantes, molestas ${ }^{24}$. As exposicións do colectivo Atlántica conectaron moi ben coas tendencias artísticas en boga na Europa do cambio de década, aglutinadas baixo o selo do neoexpresionismo, e coas novas formas de cultura popular asociadas a estas subculturas. Estas derivas nas formas de cultura popular pódense percibir en proxectos como o comic Esquizoide (Fig. 4) de Patiño, caracterizado por un debuxo nervioso e a combinación de formas recoñecibles e trazos caóticos.

\section{Os catalizadores}

Para que os desexos e inquedanzas dos artistas se puidesen materializar en forma de iniciativas culturais precisábase algo máis que espírito de camaradería. Neste caso debemos salientar o labor de certas persoas que conseguiron transcender os límites do grupo local e conseguiron mobilizar as enerxías de artistas residentes noutras cidades e colaboradores de institucións públicas. Certas persoas, ademais de aglutinar en torno a eles aos artistas, souberon prender a mecha das exposicións e dos catálogos, e conseguiron así mesmo os textos ou a participación en debates de críticos, en ocasións vidos de fóra de Galicia, como foi o caso de Antonio Bonet Correa.

Ángel llarri, conservador do Museo de Castrelos de Vigo, foi un dos impulsores das exposicións da Praza da Princesa, entre o 1968 e o 1976, unha vez que recibiu a proposta de parte dalgúns artistas locais, a finais dos anos sesenta ${ }^{25}$. O seu entusiasmo e apoio incondicional, para que as pinturas e esculturas puidesen ocupar a céntrica praza viguesa, serán destacadas polos artistas participantes. A nómina de artistas chegou a ser do máis amplo, e adoleceu dunha definición endeble, pero foi unha maneira de achegar a arte á rúa, aos cidadáns. Estas exposicións enmárcanse no fenómeno que definirá ás primeiras fases das políticas culturais da Europa occidental, de "democratización cultu- 


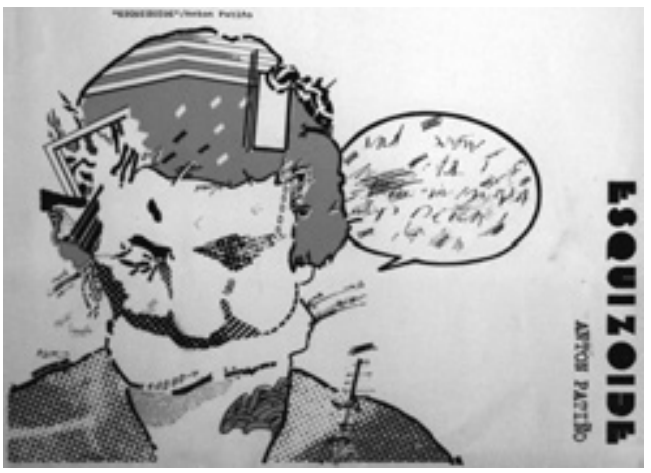

Fig. 4. Antón Patiño: Esquizoide (portada do comic), Edición do Colectivo da Imaxe, Vigo, 1978.

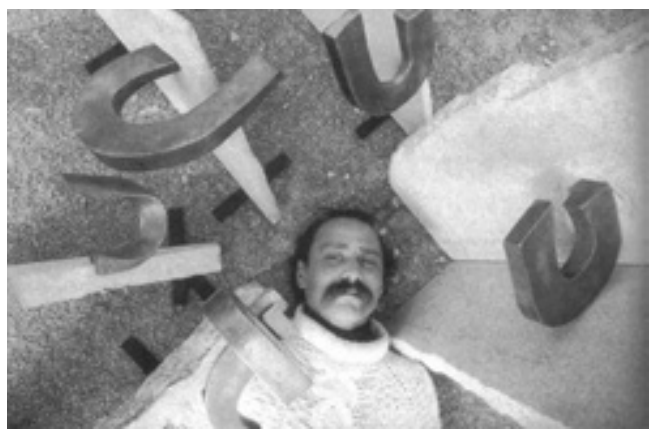

Fig. 5. Mon Vasco, fotografiado coa súa obra S/T, (6 pezas de granito e bronce, 1980-83). Colección Museo de Belas Artes de A Coruña. ral", segundo a clasificación de Esping-Ander$\operatorname{sen}^{26}$. Este primeiro estadio, que en Europa viña producíndose desde os sesenta, caracterizábase pola vontade das institucións de poñer ao servizo da poboación (das masas) a cultura contemporánea, que ata entón era patrimonio case exclusivo das elites. Pero á vez hai trazos que poden ser vistos como máis propios do seguinte estadio, o da "democracia cultural": a idea de que os cidadáns e os propios artistas xestionen estes proxectos culturais. Antón Patiño, que chegou a participar moi activamente na organización da última edición, enmarcaba estas exposicións da Praza da Princesa dentro do ambiente de "cultura de tertulias" e de bares da cidade dos setenta ${ }^{27}$.

Cando na primavera de 1980 Guillermo Monroy, Ánxel Huete, Antón Patiño e Menchu Lamas realizan a súa viaxe a Nova York, a idea de organizar unha exposición cos artistas máis avanzados da Galicia de entón acaba por se consolidar. Logo viría a chamada ao coleccionista Román Pereiro para que apoiara o proxecto e facilitara os contactos necesarios a nivel institucional, porque nel se vía a unha das poucas persoas ben relacionadas capaces de apostar por un proxecto tan ambicioso ${ }^{28}$. Pero estes son só algúns dos protagonistas máis activos. Do grupo vigués que proxectou Atlántica a idea rapidamente se estendeu a outros círculos: na Coruña Xavier Correa Corredoira, Xaime Cabanas e Mon
Vasco (Fig. 5), en Pontevedra Manuel Moldes, en Ourense Ignacio Basallo. Uns artistas chamaron por outros, e así sucesivamente. Como no caso das exposicións na Praza da Princesa, foron as afinidades persoais e unha certa noción compartida de modernidade os criterios que fixeron incluír a artistas nas exposicións. Antón Goyanes fala dunha sorte de democracia interna nas decisións dos comités das mostras da Praza da Princesa, polo menos nas súas últimas edicións, e de igual xeito os participantes nas exposicións de Atlántica salientan esta liberdade e espírito de colaboración na preparación dos eventos. As propostas que se fixeron contaron, polo xeral, co beneplácito do grupo, e o recordo desta camaradería puido ser o que motivou, anos despois, os recelos dalgúns dos participantes nas exposicións cando a Xunta empezou a montar outras baixo o marchamo da "xeración Atlántica" ou do "atlantismo" cun comisario que decidía quen debía estar presente e quen non.

Algúns dos membros máis activos que participaron na organización da primeira das mostras de Atlántica, a de 1980, tiñan experiencia na xestión de exposicións. Era o caso de Ánxel Huete, Antón Goyanes ou Silverio Rivas coas mencionadas da Praza da Princesa, e a de Escultura ao Aire Libre de 1974. Pero tres dos que será denominado co tempo "núcleo fundador" —Antón Patiño, Menchu Lamas e Guillermo Monroy-, eran aínda moi novos ese ano. 
A situación era moi complicada se eras novo — recorda Menchu Lamas-, e decidimos tomar a iniciativa sen depender dos demais. (...) Moitas veces reuniámonos na nosa casa. Cada un ía dicindo xente que coñecía da nosa xeración e da que respectabamos o seu traballo, coa que conectabamos. Entón preguntámonos por que non convidar a unha serie de xente e intentar facer algo, e de aí, onde facelo, como facelo e como podiamos dar corpo a iso. Ánxel e Guillermo coñecían a un coleccionista que se interesaba pola arte e nos podía orientar á hora de poñer en marcha as ideas. Falamos con Román Pereiro, gustoulle a idea e dixo que ía intentar conseguir algún espazo. E conseguiuno en Baiona ${ }^{29}$.

Dúas figuras ían ser destacadas pola súa capacidade mobilizadora dentro dos grupos: o vigués Guillermo Monroy e o coruñés Mon Vasco. Os dous eran bastante novos daquela, pero conseguiron ilusionar e xuntar a creadores que nalgúns casos os avantaxaban en idade. A importancia que acadou o fenómeno Atlántica debeuse en boa medida á escala do grupo, que rompía coas dinámicas localistas para se converter nunha panorámica dos artistas máis avanzados do momento en Galicia, mantendo unha certa coherencia estética, "modernizadora", pese á diversidade de linguaxes. Foi fundamental a boa conexión cos artistas coruñeses que, como sinalabamos máis arriba, levaban tempo cohesionados, ao redor de sucesivos grupos, nos que os artistas e escritores compartían experiencias - estaban presentes os escritores Xavier Seoane e Manuel Rivas.

\section{Políticas culturais}

O éxito de crítica e público das sucesivas edicións de Atlántica viña acompañado dun certo ton amargo e reivindicativo, que se reflectía nos textos e declaracións dos artistas e promotores, e nos da crítica máis afín. Román Pereiro facía unha chamada de atención ás institucións no limiar do catálogo "Huete/Lamas/Monroy/Patiño", de 1982:

Es hora ya de que los organismos oficiales dejen de acudir a sus obligadas y altas citas con el pasado y se comience a revitalizar el país con las formas de ser y sentir el mundo de hoy. Lo primero que deberían ver los que se aíslan, los que retroceden, los que sienten un reflejo de huida ante algo que no comprenden, es el gran desfase histórico de Galicia con el desarrollo de la cultura universaßo.

Pouco despois Xavier Seoane incidía doutra volta na mesma reclamación de apoio institucional con motivo da presentación de Atlántica '83, no Pazo de Xelmírez de Santiago de Compostela ${ }^{31}$. Un ano despois desta última edición a Xunta de Galicia botou a andar, co que sería o inicio das políticas culturais a escala autonómica, con programacións que mantiñan unha certa periodicidade, publicacións e profesionais da xestión e administración cultural. Desde entón entrouse rapidamente nunha nova dinámica na promoción da arte, tanto na faceta da difusión como da produción e, ademais, na de elaboración dos discursos teóricos. Imaxes dos 80 desde Galicia (Santiago de Compostela, 1984), comisariada por Xosé Antón Castro, ía ser a exposición que marcara o inicio desta nova etapa. No mesmo ano, Castro prepara outra mostra que acaba de poñer os alicerces do discurso "atlantista": Encontros no espacio. Escultores galegos dos oitenta. Estas eran exposicións colectivas que continuaban en liñas xerais coa estética predominante nas edicións de Atlántica, incluíndo a moitos dos presentes naquelas, e engadindo novos nomes que acentuaban unha liña que se pretendía neoexpresionista (Francisco Leiro e Manolo Paz serán desde entón nomes imprescindibles). Tamén nese 1984 a Xunta prepara un catálogo para a representación galega na madrileña feira ARCO de arte contemporánea (Artistas galegos en ARCO 84). Estes son os anos da presenza de Xosé Antón Castro como responsable de exposicións e Luis Álvarez Pousa como Director Xeral de Artes Plásticas, na Consellería de Cultura. Esta nova etapa da historia da arte galega virá caracterizada, ademais da mencionada promoción institucional a cargo da Xunta, polo éxito comercial e de crítica dalgúns dos participantes nas edicións de Atlántica (os máis novos, de feito): os pintores Antón Patiño, Menchu Lamas, Lamazares e Freixanes (Fig. 6), e a cre- 


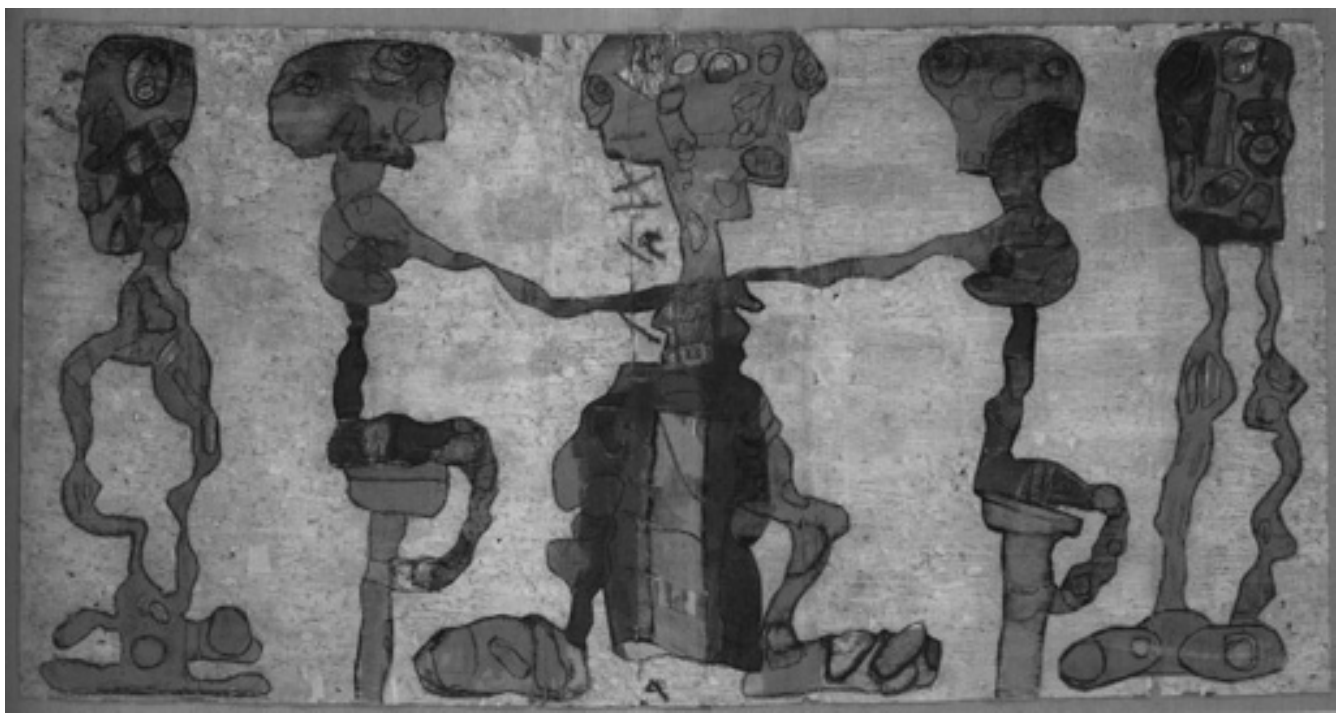

Fig. 6. Antón Lamazares: Cuento zamorano, Técnica mixta sobre cartón, 132 × 235 cm, 1981. Colección particular.

cente importancia de escultores que se foron incorporando progresivamente ás exposicións da década, e que darán lugar a unha especie de "selo" galaico, ben identificado tanto dentro como fóra de Galicia, caracterizado pola utilización maioritaria de materiais tradicionais e con xeitos de traballo achegados á tradición dos oficios populares: Francisco Leiro, Manolo Paz, Paco Pestana, Xosé Manuel Castro, Luis Borrajo e Ignacio Basallo. Este é o contexto do discurso do genius loci de Xosé Antón Castro, que defendía ideas tales como a de que primitivismo, "expresionismo vivencial" e o sentimento romántico eran características innatas aos artistas galegos e se evidenciaban desde a prehistoria —os labirintos e espirais celtas, a arte de canteiros populares, o románico, etc. ${ }^{32}$. E a través dos trazos formais se evidenciaría - sempre seguindo o discurso do crítico e comisario-, a esencia propia dunha arte "indefectiblemente galega":

O atlantismo galego espéllase na arte dos oitenta dunha maneira totalizadora, cando o creador non está mediatizado polos prexuícios de búsquedas apriorísticas de lin- guaxes alleas como outrora se reflectiu nos artistas do primeiro tercio de século... Porque os elementos que definen a identidade plástica, á marxe dos contidos, son as formas e os conceptos, a luz, a cor, o espírito ou o sentido emocional; e iso se falan con unha linguaxe indefectiblemente galega (sic.) ${ }^{33}$.

O discurso de Xosé Antón Castro cumpriu con eficacia dous obxectivos: por unha banda xustificar a política de promoción da arte da primeira Xunta de Galicia, cando aínda as estruturas administrativas e os programas culturais estaban por facer, e por outra equiparar as novas tendencias da arte galega coas que estaban en boga noutros países; de aí a énfase en comparar co espírito neoexpresionista alemán e coa transvangarda italiana. A arte nova galega estaría pois navegando entre o autóctono e as novas correntes internacionais, con total coherencia e enganchándose ao espírito dos tempos (Fig. 7). Era unha arte o suficientemente diferenciada e peculiar — por unha banda-, pero á vez presentábase como perfectamente homologada coas linguaxes internacionais. Non é esta estratexia da "diferenciación homologada" a xenuina 
das administracións cando se trata de promocionar culturas ou cidades para o turismo cultural? $?^{34}$

No trasfondo estábase a dar unha transformación salientable no referido ás políticas de promoción cultural: nos primeiros anos oitenta constátase un maior peso das Comunidades Autónomas na xestión dos fondos e nas actuacións, véndose isto acompañado dun incremento significativo dos orzamentos dedicados a cultura, no total das administracións. Sumando as achegas do Ministerio de Cultura e das Comunidades, pasouse en España de 11.350 millóns das antigas pesetas en 1978, a 29.800 en 1984 35 ; ou sexa, que en seis anos case se triplica o orzamento destinado a cultura.

O sociólogo Xan Bouzada apunta como fenómeno característico das comunidades que contan con lingua propia —as denominadas "nacionalidades históricas"-, a asociación entre promoción da cultura e lexitimación do poder autónomo ${ }^{36}$. Nestes casos - Galicia, País Vasco e Cataluña-, as administracións tomaron como elemento estratéxico o ámbito da cultura, e a través da utilización de símbolos identitarios e da defensa, recuperación e mesmo "invención" de tradicións, traballaron na xustificación da diferenza e das súas peculiaridades políti$\mathrm{cas}^{37}$. A cultura foi vista polas autonomías como valor estratéxico e instrumento de lexitimación. Aquí a defensa dunha cultura propia estaría unida á reclamación de máis competencias en ámbitos do máis dispar, de máis autogoberno. Así é como se entenden situacións paradoxais como a que se deu en Galicia durante os sucesivos gobernos do Partido Popular, que asumiu posicións culturais e símbolos que os achegaban ao nacionalismo moderado. A arte non escapaba desta dinámica. O labor e os discursos desenvoltos desde a Consellería de Cultura, desde o primeiro goberno da Xunta, hainos que enmarcar polo tanto nesta tarefa de lexitimación do novo poder, implicando desde a utilización de símbolos (bandeira, lingua, escudo...) ata tópicos que poderían servir para identificar e cohesionar á comunidade ${ }^{38}$.

Na década dos oitenta, coa aparición dos primeiros programas culturais autonómicos, deuse tamén o fenómeno do solapamento nas actuacións con outras administracións. Isto afectou á organización de exposicións, á xestión de muse-

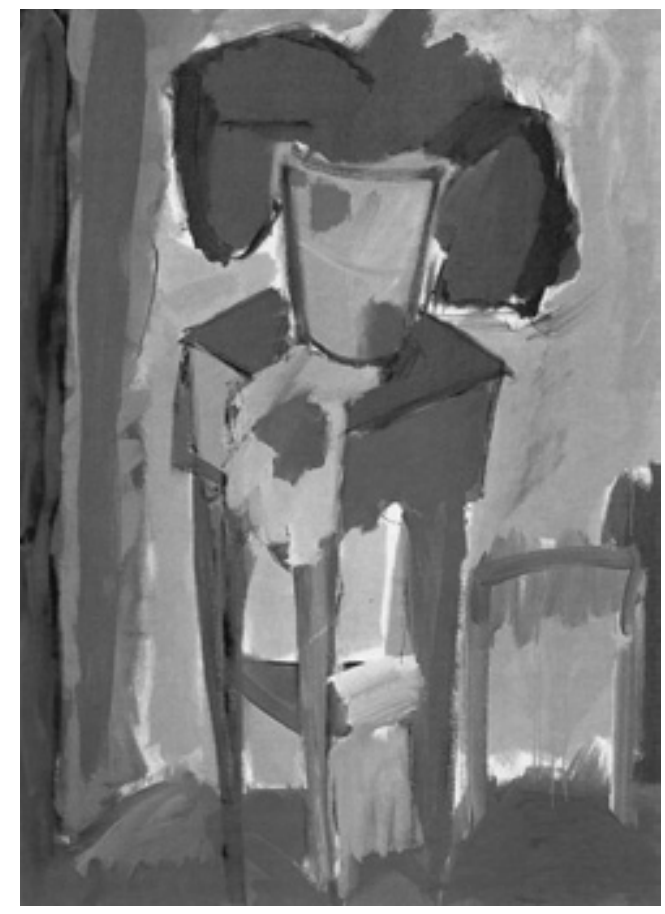

Fig. 7. Guillermo Monroy: Maceta, Acrílico sobre tea, $130 \mathrm{x}$ 97 cm., 1982. Colección Museo Municipal Quiñones de León, Vigo.

os e á promoción da creación contemporánea coas bolsas para novos creadores. Á altura de 1992 un documento de traballo, Las relaciones entre el Estado y las Comunidades autónomas en materia de cultura, intentaba clarificar as competencias neste ámbito no que todos —administración estatal, autonómica e local- parecían poder facer de todo ${ }^{39}$. No libro alúdese explicitamente ás ambigüidades do artigo 149.1.28 da Constitución Española que regula as competencias en cultura do Estado. O artigo deu pé a interpretacións, posto que indica que preferentemente o Estado asume competencias de xestión e administración de museos e bibliotecas de interese xeral ${ }^{40}$, e deixa para as autonomías as tarefas de "promoción" da arte e a cultura. A sentenza 49 / 1984 do Tribunal Constitucional tentou mediar nos litixios que se empezaban a producir: establecía que as competencias non son excluíntes no eido da cultura 
- a diferenza doutros eidos-, e abogaba por que as CC.AA. se ocupasen do "fomento da cultura" e o Estado do "servizo da cultura" 41.

Puido isto derivar nunha maior énfase na promoción da arte a través de exposicións nas Comunidades Autónomas? No caso de Galicia así o parece, porque a Xunta dos primeiros anos carecía de competencias sobre museos e dos recursos necesarios para erixir outros novos, coas súas coleccións e o seu persoal, pero pola contra, puido facer un importante esforzo en promoción da arte a través de exposicións e de bolsas. O caso é que á altura de 1992, chama a atención a "necesidade" da aparición deste libro branco, que comeza cunha apelación directa á necesidade de ordear competencias e distribuir funcións, entre as administracións ${ }^{42}$.

O discurso "lexitimador" da diferenza cultural das primeiras iniciativas de promoción artística da Xunta será contestado en poucos anos polos mesmos artistas que protagonizaran as actividades "autoxestionadas" dos setenta e principios dos oitenta, reticentes a ser encadrados dentro destes parámetros. Entre os que participaran nas exposicións aparecerán voces críticas ante esta aparente "etapa dourada" para a arte contemporánea de Galicia. Ignacio Basallo xa no 1990 aludía aos perigos dunha excesiva dependencia institucional ${ }^{43}$, e Xavier
Correa Corredoira amosaba as súas críticas de xeito máis explícito, contra o control que de facto exercían certas figuras desde as institucións na selección de artistas para exposicións colectivas: eles eran os que agora decidían quen estaba e explicaban ao gran público as claves da súa arte, establecendo as interpretacións canónicas ${ }^{44}$.

A exposición que en 2002 conmemoraba no MARCO de Vigo ao movemento Atlántica xa necesariamente tiña que ser outra cousa, moi diferente do espírito autoxestionado e colectivo dos oitenta. Polo medio interpuxérase toda unha estrutura institucional artellada pola Xunta, principalmente, pero tamén polas outras administracións, cunha complexa rede de centros, administradores e xestores, servindo de contexto a eventos e discursos da singularidade creativa, nun novo contexto de competición nas programacións. Estes xestores que median entre artistas, comunidades e fontes de financiación, acabaron por profesionalizar as iniciativas artísticas e anular o seu carácter espontáneo e ilusionado ${ }^{45}$. De aí o desencanto dos artistas veteráns ao ver "traizoado" o seu impulso colectivo; de aí as desconfianzas dos artistas novos máis implicados que, case trinta anos despois, parecen retomar as vellas ilusións e o ideal de traballo colectivo e precario.

\section{NOTAS}

\footnotetext{
${ }^{1}$ Ver o catálogo da mostra: Atlántica. Vigo. 1980-1986, Museo de Arte Contemporánea de Vigo, Vigo, 2002. As exposicións colectivas realizadas baixo a denominación "Atlántica" foron as seguintes: Atlántica '80 (Baiona, Pontevedra, 1980), Atlántica, o feito plástico (Vigo, 1981), Atlántica '81 (Madrid, 1981), Doce pintores de Atlántica (Salvaterra de Miño, Pontevedra, 1982) e Atlántica '83 (Santiago de Compostela, 1983).

2 Ver: "Xornadas Atlánticas, 1 e
}

2", en D. Barro e C. Vidal, Voces de Atlántica, Fundación MARCO / Editorial Galaxia, Vigo, 2005.

${ }^{3}$ Ibid., p. 288-289.

${ }^{4} \mathrm{O}$ tema das relacións arte-pobo e a necesidade de fortalecemento da comunicación aplicada ás iniciativas artísticas estaba moi vixente nos debates artísticos en España desde finais dos sesenta. Desde as traducións de ensaios de estética marxista e de historia social da arte, ata as polémicas entre realismo e abstracción, que virían a marcar os anos setenta. Cfr. V. Bozal e T. Lloréns, España, vanguardia artística y realidad social: 1939-1976, Barcelona, Gustavo Gili, 1976.

${ }^{5}$ Estas declaracións están recollidas no libro de entrevistas de D. Barro e C. Vidal, Voces de Atlántica..., op. cit.

${ }^{6}$ Francisco Leiro, entrevistado por David Barro en Voces de Atlántica..., op.cit., p.131.

${ }^{7}$ Entendemos o concepto de arte oficial de xeito semellante ao de Albert Boime cando reflexiona sobre os procedementos de ensino na academia: a arte oficial, sendo tradicional en moitos aspectos, diferenciaríase da acadé- 
mica por acoller certas doses de modernidade. Os heteroxéneos xurados de exposicións poderían admitir obras cunha certa modernidade a carón doutras moito máis tradicionais. A académica, amosaríase moito máis atada aos códigos tradicionais. A. Boime, The Academy \& French Painting in the Nineteeth Century, Yale University Press, New Haven \& London,1986, pp. 18-20.

${ }^{8}$ Antes da chegada da Xunta de Galicia, as Bienais de arte de Pontevedra eran o máis significativo evento da arte de Galicia, o máis ambicioso proxecto con respaldo institucional. En canto aos museos, só dous expuñan arte contemporánea: o Museo Carlos Maside de Sada (A Coruña) e o Museo Quiñones de León, en Vigo, e en ámbolos dous casos os mellores exemplos de arte moderna correspondían con artistas galegos relacionados coas vangardas históricas.

${ }^{9}$ G. Plaza Molina: Arte en Galicia. La década del "boom", Ediciós do Castro, Sada (A Coruña), 1980, p.16.

10 Tralo panorama raquítico de galerías dos anos sesenta, a "década do boom" presenciou a aparición de Mestre Mateo, Ceibe, Giannini e Os Arcados en A Coruña; Arco da Vella en Lugo; Ánfora, Albatros e Altamira en Pontevedra; Novecento, Abracadabra, Velázquez e Van Gogh en Vigo; Matisse, Anue, Hidea e Torques en Santiago; e Souto en Ourense. Mágoa que moitas delas a penas duraron uns anos.

${ }^{11}$ I. Lorey, "Gubernamentalidad y precarización de sí. Sobre la normalización de los productores y productoras culturales", en Proyecto Transform, Producción cultural y practicas instituyentes. Líneas de ruptura en la crítica institucional, Traficantes de sueños, Madrid, 2008, pp. 72-74.

${ }^{12} \mathrm{X}$. Correa Corredoira, en $\mathrm{X}$. Seoane, Identidade e convulsión. Palavra e imaxe da arte galega, Ediciós do Castro, Sada (A Coruña), p.93.

${ }^{13}$ No manifesto fundacional do grupo Sisga podía lerse: "Pertenecemos a diversas generaciones y tenden- cias artísticas; estamos unidos por el deseo de difundir y popularizar un arte que trate de ser actual. Hoy en día, ante la desorientación existente, debida en su mayor parte a la falta de información clara y divulgadora, se impone un tipo de iniciativas que intente en lo posible ordenar y precisar conceptos". Cit. en Plaza Molina: Arte en Galicia..., op.cit., p.19.

${ }^{14}$ X. Ron: "O mito do caralludo (un invento progre dos 70)", en 0 lado da sombra: sedición gráfica e iniciativas ignoradas, raras ou desacreditadas entre 1971 e 1989, Fundación Luis Seoane, A Coruña, 2005, pp. 216-217.

15 Presentación do catálogo da Exposición de Pinturas ao Aire Libre da Praza da Princesa, Vigo, 1976; cit. por Antón Goyanes, en "Xornadas Atlánticas 1", en Voces de Atlántica..., op.cit., p.270.

${ }^{16}$ Ibídem.

${ }^{17}$ W. Benjamin, "Charles Baudelaire. Un lírico en la época del altocapitalismo", en W. Benjamin, Obras. Libro / / vol.2, Abada Editores, Madrid, 2008, pp 91-120.

18 Antón Patiño alude a unha continuidade "natural" entre as dúas iniciativas: "Realmente Atlántica naceu a partir dunha sinxela aleación onde se mesturaron os artistas máis innovadores da mostra "oficial" da Praza da Princesa cos emerxentes de "Princesa '76"; de xeito que á relación de nomes sinalados denantes incorporáronse Lodeiro, Huete, Mantecón, Goyanes, Armando Guerra e Silverio Rivas... Logo virían as incorporacións de Leiro, Baixeras, X. Vázquez, Basallo, Mon Vasco, Cabanas, Corredoira, dende outras áreas xeográficas". A. Patiño, "Ángel Ilarri", Castrelos, n 11, 1998, p. 45.

${ }^{19}$ Sobre as exposicións da Praza Princesa dirá Goyanes: "...a implicación dos artistas nas exposicións en que participaban era practicamente total. Organizabamos e expoñiamos; xestionabamos axudas económicas, escasas e, nalgúns casos, fracasadas; transportabamos as obras como podiamos, habitualmente sen seguro (...). Esta situación acontecerá tamén nos tempos de Atlántica, aínda que neste caso suavizada pola presenza e presidencia de Román Pereiro". Goyanes, en "Xornadas Atlánticas 1", en Voces de Atlántica..., op.cit., p.269.

20 Antón Reixa: "Oceanografía sentimental. (Sete claves soltas para pensar no que pasaba artisticamente nesta parte do Atlántico no principio daqueles alegres 80)", en Atlántica. Vigo. 1980-1986..., op.cit., p.257.

${ }^{21}$ Estes creadores estaban á altura de 1978 integrados en colectivos: Patiño no Colectivo da Imaxe e Reixa no grupo literario Rompente. En ámbolos dous casos as creacións eran en moitos casos colectivas e o impulso era provocativo nas realizacións.

${ }^{22}$ Ver X. González-Millán, Literatura e sociedade en Galicia (19751990), Xerais, Vigo, 1994, pp.20-35 e 146-160. O autor defende que neste período de tránsito entre os setenta e os oitenta unha nova xeración de escritores entre os que se encontran Antón Reixa, Suso de Toro e Manuel Rivas afástanse da tradición literaria adoptando outros parámetros, como son a temática urbana, a experimentación e temas como o erotismo.

${ }^{23}$ D. Hebdige, Subcultura. El significado del estilo, Paidós, Barcelona, 2004.

24 "Como tales -explica Hebdige, son gestos, movimientos hacia un discurso que ofenda a la 'mayoría silenciosa', que ponga en jaque el principio de unidad y cohesión, que contradiga el mito del consenso". Ibid., p.34.

${ }^{25}$ Ver Castrelos, no 11, 1998, no que distintos artistas do ámbito vigués dedícanlle palabras de cariño na homenaxe ao que fora director do museo Quiñones de León e impulsor de proxectos autoxestionados por artistas: as citadas exposicións da Praza da Princesa, que ían estar integrados na programación nas festas de verán da cidade, e a Exposición de Escultura ao Aire Libre de 1974, na que se puideron ver obras de Chillida, 
Andreu Alfaro e Chirino, xunto coa dos escultores galegos máis avanzados do momento.

${ }^{26}$ A. Ariño Villaroya, X. Bouzada, A. Rodríguez Morató: "Políticas culturales en España", en Juan A. Roche Cárcel y Manuel Oliver Narbona (eds.).: Cultura y globalización. Entre el conflicto y el diálogo, Publicaciones Universidad de Alicante, Alicante, 2005, 435-472. Rodríguez Morató toma esta clasificación de Gosta Esping-Andersen.

${ }^{27}$ Estes aínda eran lugares importantes na vida cultural das cidades -son os casos de míticas tabernas e cafés como O Elixio en Vigo, Bar Tucho en Ourense ou o Carabela en Pontevedra. En Vigo, ademais, a librería do pai de Antón, Librouro, foi un centro importante para o intercambio de publicacións e informacións sobre arte moderna. Antón Patiño, entrevista co autor, en Vigo, 24 de abril de 2010.

28 Antón Patiño, entrevista co autor en Vigo, 24 de abril de 2010.

${ }^{29}$ Menchu Lamas, en Voces de Atlántica..., op.cit., p.111.

30 Román Pereiro Alonso: "Huete/Lamas/Monroy/Patiño" Limiar do catálogo, Vigo, 1982, en Atlántica. Vigo. 1980-1986..., op.cit., p.326.

31 "... sería interesante que os organismos competentes (Concellos, Deputación, Xunta, Fundacións...) comprendesen o interesante momento histórico que estamos a vivir culturalmente, e que se fagan eco tanto da presente mostra como de todo o que está a ocorrer no noso país, e que anuncia que algo novo está a nacer". X. Seoane: "Atlántica 83. Instinto de camiño en Xelmírez", en Atlántica'83, Santiago de Compostela, 1983.

32 A mellor exposición destas características definitorias para Xosé A. Castro da arte galega ao longo do tempo recóllense no seu libro Expresión Atlántica. Arte galega dos 80 , Follas Novas, Santiago de Compostela, 1985. Ás xa mencionadas arriba habería que sumar a saudade, o panteísmo ou a "imaxinación transcendente". A liña xenealóxica xa fora anticipada por
Castelao, Otero Pedrayo e Luis Seoane, entre outros.

$$
33 \text { Ibid. p. } 27 .
$$

34 A carreira das cidades por comercializar unha determinada "imaxe" a partir de edificios singulares e dun discurso da "excepcionalidade" foi analizada polo xeógrafo David Harvey, quen apuntou a este fenómeno como característico da fase actual do capitalismo: as elaboracións da imaxe da "excepcionalidade" parecen ocupar o centro das políticas urbanas e de promoción turística das cidades, provocando o paradoxal fenómeno de que por unha banda as cidades buscan con fervor unha imaxe de si que as distinga, pero por outra, ríxense por modelos de turismo cultural cada vez máis homoxéneos, coincidentes cos de calquera outra cidade con aspiracións a acadar visibilidade. D. Harvey, "El arte de la renta: la globalización y la mercantilización de la cultura", en D. Harvey y N. Smith, Capital financiero, propiedad inmobiliaria y cultura, MACBA/ Universitat Autònoma de Barcelona, Barceona, 2005, pp.29-57.

${ }^{35}$ Datos do Ministerio de Cultura recollidos por Ariño, Bouzada y Rodríguez Morató: "Políticas culturales en España"... op.cit. p.435.

${ }^{36}$ Ibid., p.444 e ss.

${ }^{37}$ Ibidem.

38 Ver J. González Beramendi, "Os usos ideolóxicos da etnicidade. Comparación dos nacionalismos galego e español", en VV.AA., Etnicidade e nacionalismo. Simposio internacional de antropoloxía (coord. X.M. González Reboredo), Consello da Cultura Galega, Santiago de Compostela, 2001

${ }^{39}$ Las relaciones entre el Estado y las Comunidades autónomas en materia de cultura. Libro blanco, Ministerio de Cultura? (texto mecanografiado), 1992.

${ }^{40}$ Pero contemplando á vez que as autonomías poden asumir a xestión destes se hai un interese territorial evidente.

${ }^{41}$ Ibid., p. 9. E pouco máis adiante explica a sentenza que "...más que un reparto competencial vertical, lo que se produce es una concurrencia de competencias ordenada a la preservación y estímulo de los valores culturales propios del cuerpo social desde la instancia pública correspondiente". Ibid., p. 12.

42 Quérense establecer novas formas de colaboración e mesmo avógase pola creación dunha Conferencia Sectorial para establecer un novo marco de relacións. Ibíd. p. 5-6.

43 "O panorama está algo mellor... Creo, sen embargo, que estamos pecando de procurar mecenado oficial do goberno ou da Xunta, que ao final só condicionan compromisos políticos e o que fan é venderte e utilizarte". Ignacio Basallo en X. Seoane, Identidade e convulsión..., op. cit., p.43.

44 "Atlántica facilitounos unha cohesión entre nós a nivel expositivo, de combate. Deunos unha plataforma de loita. Achegounos a xente de xeracións anteriores... Creamos uns espazos expositivos, uns catálogos que son documentos, sensibilidade en determinados medios políticos, aínda que durante pouco tempo. A xente da política quere controlar todo, e non lle souberon entrar ao espírito do movemento. Durante algún tempo a nivel oficial dedicáronse a aproveitarse desa estética, cando a época de X. Antón Castro na Xunta e López Calvo en A Coruña." X. Correa Corredoira, Ibid., p.99.

${ }^{45}$ George Yúdice ten analizado as derivas do sector cultural no contexto latinoamericano, dentro desta dinámica de crecemento e profesionalización do sector cultural. Dentro desta dinámica na que o "xerenciamento" e a profesionalización está á orde do día, cabe a esperanza, que o autor ilustra con iniciativas de arte pública que logran implicar ás comunidades onde se realizan e engadir un ámbito de reflexión á vida cotiá. G. Yúdice, El recurso de la cultura. Usos de la cultura en la era global, Gedisa, Barcelona, 2002. 